\title{
DESAFIOS E CONQUISTAS DA PEDAGOGIA HOSPITALAR: A CONTRIBUIÇÃO PEDAGÓGICA NO PROCESSO DE APRENDIZAGEM DA CRIANÇA HOSPITALIZADA EM TRATAMENTO ONCOLÓGICO
}

\author{
BARBOSA, Andreza da Silva ${ }^{1}$ \\ GIMENES, Priscila Alvarenga Cardoso ${ }^{2}$
}

RESUMO: A Pedagogia Hospitalar refere-se ao conjunto de ações pedagógicas desenvolvidas no ambiente hospitalar em prol do processo de aprendizagem da criança hospitalizada possibilitando que ela não perca o vínculo com a instituição escolar que frequenta. Com o objetivo de contribuir com a construção de conhecimentos sobre este campo de atuação do pedagogo, a pesquisa busca apresentar e discutir as ações da pedagogia hospitalar destinadas a crianças em tratamento oncológico. Para tanto conta com uma pesquisa de campo realizada no Hospital AC Camargo Center, instituição de referência no tratamento oncológico e na oferta de atendimento educacional aos pacientes e que abriga uma das primeiras instituições de ensino fundada em um hospital do país, por meio da aplicação de questionários aos professores e a gerente educacional da instituição. Com a pesquisa foi possível constatar que o atendimento educacional desenvolvido junto a crianças em tratamento oncológico precisa considerar as especificidades da doença e do tratamento, visto que este é longo, invasivo e doloroso, sendo de fundamental importância a parceria com a equipe médica e com a família da criança. É relevante adequar as atividades à sua condição física e emocional, que sejam motivadoras e possibilitem que ela vivencie momentos prazerosos, sendo fundamental que os profissionais da educação que atuam nesta área possuam formação específica e se identifiquem com este trabalho. A atuação da pedagogia hospitalar junto a crianças em tratamento oncológico tem apresentado resultados positivos e merece atenção dos governantes na elaboração de políticas públicas que ampliem este atendimento.

Palavras-chave: Oncologia pediátrica. Práticas pedagógicas. Ação educativa.

SUMMARY : The Hospital Education is an Educational work which is made in a hospital with a child, to make the school possible, and he/she does not miss the link with the school where he/she studies and goes on the learning process. The aim of this research is to contribute with the construction of knowledge about this area of the teacher's performance, and to discuss about educational practices drawn up and carried out in a hospital context whose teacher's work is to teach children who is in a treatment of cancer. In the beginning, a bibliography research was carried out, and then, a field research in the AC Camargo Center Hospital, by means of questionnaires to teachers and coordinator who work in a school. Such place has been relevant to the study to refer to a treatment of cancer, and to keep itself one of the first educational institution founded in a hospital. According to the theoretical references, it was noted the necessity of multi/inter/transdisciplined work to help the child in the hospital, because the education is one of the relevant components of this proposal. However, it is necessary to consider the specificity of the treatment of cancer, which orders a different educational work for the child's psychological aspects, because this disease requires an aggressive and painful treatment. In many cases, the child withdraws easily, so the learning process becomes difficult. Therefore, the developed activities must give the children a change to feel quite happily and motivated to participate of the offered work. As a result of the research, it was checked the importance of the educational practices carried out in the hospital, also extreme importance the teacher's participation in the treatment of the cancer to enter in the society again.

Keywords: Pediatric oncology. Educational practices. Education action.

\footnotetext{
${ }^{1}$ Faculdade de Filosofia, Ciências e letras de Ituverava

${ }^{2}$ Universidade Federal de São Carlos

Faculdade de Filosofia, Ciências e letras de Ituverava
} 


\section{INTRODUÇÃO}

A Pedagogia Hospitalar refere-se às práticas pedagógicas exercidas no contexto hospitalar, com o intuito de beneficiar as crianças ou adolescentes que se encontram afastados da escola devido a internações.

As primeiras iniciativas de atendimento educacional desenvolvido no contexto hospitalar datam meados da década de 1930 na França e posterior implantação em outros países. Registra-se marcante projeção deste atendimento após a Segunda Guerra Mundial devido ao saldo de crianças e adolescentes doentes ou mutilados que estavam impossibilitados de frequentar a escola. No Brasil, a primeira classe hospitalar foi implantada em 1950, em um hospital da cidade do Rio de Janeiro. Desde então este atendimento vem sendo, timidamente, implantado em outros hospitais do país.

As ações da pedagogia hospitalar tem se mostrado relevantes, sobretudo nos casos de internações longas, como acontece com a oncologia pediátrica. Entretanto esta área carece de estudos e pesquisas que possibilitem divulgação do trabalho realizado e a construção de conhecimentos sobre as práticas pedagógicas desenvolvidas junto a crianças em tratamento oncológico.

Com o intuito de contribuir com a construção de conhecimentos sobre as ações da pedagogia hospitalar desenvolvida junto a crianças e adolescentes em tratamento oncológico foi realizada uma pesquisa de campo ${ }^{3}$ no Hospital AC Camargo Cancer Center, que é uma referência no país, sobretudo por sediar uma escola especializada em atendimento pedagógico hospitalar, a Escola Especializada Shwester Heine da Fundação Antônio Prudente. A pesquisa foi planejada com o objetivo de conhecer o trabalho desenvolvido pelos profissionais que nela atuam, bem como os resultados deste trabalho junto aos alunos em tratamento oncológico.

A pesquisa contou com uma abordagem qualitativa e foi realizada a partir de uma pesquisa bibliográfica seguida de uma pesquisa de campo na referida escola, utilizando-se de dois questionários, sendo um destinado à gestora educacional e outro aos professores que atuam na escola, além de visitas à escola para conhecer o trabalho desenvolvido.

A realização da pesquisa possibilitou compreender como as propostas pedagógicas são desenvolvidas no contexto hospitalar, a importância do planejamento de atividades que motivem a criança a participar e do estabelecimento de parceria com a equipe médica e com a família da criança. Também possibilitou verificar que este atendimento auxilia no enfrentamento da situação da enfermidade por parte da criança e do adolescente sem privá-los de vivências importantes, como é o caso do engajamento em situações de aprendizagem.

\section{A PEDAGOGIA NO HOSPITAL - OS NOVOS RUMOS DA PRÁTICA DOCENTE}

A Pedagogia Hospitalar é uma área da Pedagogia que propõe a atuação do pedagogo no contexto hospitalar, visando contribuir com o desenvolvimento de crianças e adolescentes que, por algum motivo, encontram-se hospitalizados e, por consequência, afastados da escola, seja por curto ou por períodos prolongados. Neste campo profissional da educação, o pedagogo desenvolve um processo educativo não escolar que possibilita a construção de novos conhecimentos.

Esta proposta visa cumprir duas funções que são: melhorar a qualidade de vida das crianças e adolescentes em situação de internação, contribuindo para uma recuperação mais rápida e, também, dar continuidade nas atividades desenvolvidas pela escola, para que o aluno não tenha grandes prejuízos com o seu afastamento. Visto que de acordo com Matos e Mugliatti (2009, p. 27):

\footnotetext{
${ }^{3}$ Aprovado no Comitê de Ética - CAAE- 53543216.4.0000.5405
}

Nucleus,v.14,n.2,out.2017 
[...] a privação da escola e do convívio salutar com seus companheiros pode acarretar ilimitados prejuízos à criança (ou adolescente) hospitalizada, traduzidos em traumas e, muitas vezes, até alteração de conduta, diante das limitações impostas pelo ambiente hospitalar

Para Ortiz e Freitas (2005), a Pedagogia Hospitalar constitui-se em um direito previsto em lei que possibilita o fortalecimento individual do paciente, a conquista da autonomia e a construção de conhecimentos por meio da realização de atividades e tarefas interdisciplinares e construtivas dentro do ambiente hospitalar.

Neste sentido, a pedagogia hospitalar vem se mostrando relevante, por contribuir com o tratamento de crianças e adolescentes em situação de internação, e torna-se uma importante área de atuação para os pedagogos.

As ações da Pedagogia Hospitalar tiveram início, de acordo com Esteves (2008), no ano de 1935, em Paris, quando o francês Henri Sellier, criou a primeira instituição de ensino para crianças que não podiam frequentar a escola devido à tuberculose. Com o incentivo de médicos, religiosos e voluntários, o atendimento educacional voltado para crianças e adolescentes hospitalizados foi implantado em diversos países. O grande marco da ampliação dos atendimentos da Pedagogia Hospitalar foi a Segunda Guerra Mundial devido a necessidade de disponibilizar algum atendimento escolar para a expressiva quantidade de crianças e adolescentes mutilados nos confrontos e impossibilitados de frequentar a escola.

No Brasil, a primeira experiência da inserção da Pedagogia Hospitalar ocorreu em 1950, no Hospital do Menino Jesus, instituição municipal da cidade do Rio de Janeiro. Devido aos resultados satisfatórios alcançados com o trabalho da classe hospitalar, em 1960, o Hospital Barata Ribeiro, localizado na mesma cidade, instalou sua primeira classe hospitalar. Desde então a prática docente inserida no contexto hospitalar ganhou repercussão no país, passando a despertar o interesse de diversas instituições hospitalares, principalmente após a promulgação da Constituição Federal de 1988 e do Estatuto da Criança e do Adolescente - Lei n.8.089, de 1990, houve o entendimento sobre a obrigatoriedade do atendimento educacional hospitalar.

Outros dispositivos legais que tornam o atendimento da pedagogia hospitalar obrigatório são a Política Nacional de Educação Especial, que utilizou a nomenclatura da Classe Hospitalar, sendo reconhecida como modalidade de atendimento educacional às crianças e jovens, necessitadas de educação especial e que estejam em tratamento hospitalar (BRASIL, MEC/SEESP, 1994); a Resolução $n^{\circ}$ 41/1995 do Conselho Nacional da Criança e do Adolescente - CONANDA, que institui os Direitos da Criança e do Adolescente Hospitalizado e salienta no item 90: "Direito de desfrutar de alguma forma de recreação, programas de educação para saúde, acompanhamento do currículo escolar durante sua permanência hospitalar." (BRASIL, 1995, p.1); e a Lei de Diretrizes e Bases da Educação Nacional - LDB 9394/96 (BRASIL, 1996) propõe que sejam disponibilizadas todas as oportunidades possíveis para que os processos de desenvolvimento e aprendizagem não sejam suspensos, cabendo às unidades escolares estabelecer uma parceria com as instituições hospitalares e quando possível, com o pedagogo hospitalar para a realização do atendimento educacional às crianças privadas de frequentar a escola.

Embora a Pedagogia Hospitalar contribua para o cumprimento de um dispositivo legal e resulte em benefícios para as crianças e adolescentes, de acordo com uma pesquisa realizada por Fonseca (2008) no Brasil, apenas onze estados disponibilizam em alguns de seus hospitais o serviço da pedagogia hospitalar por meio da implantação das classes hospitalares. Quando considerada a oferta do atendimento destinado a pacientes em tratamento oncológico, Assis (2009) localizou treze instituições em todo o país na época da pesquisa. Estas pesquisam apontam para a necessidade da implantação de políticas públicas que incentivem os hospitais a disponibilizar este serviço, visto que é um importante recurso na 
luta contra a doença, bem como afirmam Ortiz e Freitas (2005, p. 49):

Há uma intencionalidade nesta ação: a luta contra a doença, não com arsenal curativo da medicina, mas, antes, com uma atenção escolarizada, armada com anseios de crescimento pessoal, investindo na criatividade, na busca de caminhos novos e na geração de expectativas de realização.

Há uma obrigatoriedade neste momento, na qual, é clara a importância de se enfrentar todos os desafios necessários para que este trabalho seja concretizado de forma que todos tenham acesso, pois a educação não pode ser um direito negligenciado. De acordo com Fonseca (2008, p.17): “A criança é, antes de qualquer coisa, um cidadão que, como qualquer outro, tem direito ao atendimento de suas necessidades e interesses mesmo quando está com sua saúde comprometida”, ou seja, a criança tem que ser respeitada, em qualquer situação que se encontra, estando saudável ou doente.

\section{O PEDAGOGO HOSPITALAR: TRILHANDO CAMINHOS HUMANIZADOS ENTRE SAÚDE E EDUCAÇÃO}

A atuação do pedagogo em ambientes hospitalares contribui para a continuação do ensino e da aprendizagem das crianças e adolescentes hospitalizados, além de proporcionar novas oportunidades de aprendizagem. A adequada formação do pedagogo é fundamental, pois segundo Hanze (2011), este profissional deve ser preparado para lidar com as adversidades e agir com maior flexibilidade com relação ao número de crianças que vai trabalhar, o tipo de atividade, o currículo, além de levar em consideração o tempo de internação, a condição física e emocional e as peculiaridades do tratamento, bem como afirma Fonseca (2008, p.29): "O professor da escola hospitalar é, antes de tudo, um mediador das interações da criança com o ambiente hospitalar".

Este profissional precisa reunir diversas habilidades e competências e construir outras, ao longo de sua experiência profissional, tanto no que diz respeito a conteúdos, metodologias, estratégias e recursos didáticos, quanto em relação aos aspectos emocionais, além de possuir conhecimentos sobre os quadros clínicos apresentados pelos alunos/pacientes para que os resultados de sua atuação sejam positivos e contribuam com a recuperação da criança e do adolescente hospitalizado. Mattos e Mugliatti (2009) afirmam que este campo da pedagogia exige do profissional uma postura diferenciada, pois provoca impactos diretos na vida dos alunos/pacientes sob sua responsabilidade. Para Matos (2010, p.46):

O professor, para atuar em ambiente hospitalar, deve apresentar ampla experiência pedagógica, flexibilidade de trabalho, que irão completar seu perfil para o ambiente hospitalar, deparando-se com mudanças diárias nas enfermarias em que crianças internadas saem de alta ou entram em óbito. Diariamente ao chegar às unidades de internação pediátricas cirúrgicas, oncológicas, deverá estar preparado para avaliar em curto prazo e ofertar conteúdos dirigidos, a idade, ambiente, condições físicas e psicológicas, contaminação e, sobretudo, o tempo de aprendizagem de cada indivíduo.

Fonseca (2008) ressalta que o pedagogo hospitalar necessita de formação específica para atender a todas as exigências encontradas no seu campo de atuação, sendo um dos grandes diferenciais, as informações sobre doenças e tratamentos e o controle emocional. Melnik e Kácia (2015, p. 36-37) ressaltam que: "O pedagogo hospitalar precisa ter um equilíbrio emocional para manter a integridade da sua saúde física e emocional, uma vez que seu trabalho pode ser desenvolvido nos mais diversos setores" e Assis (2009, p.106) aponta que: "[...] além de sua experiência anterior, precisa adquirir competências específicas - sempre aliadas a um olhar diferenciado e uma escuta sensível - para o 
exercício responsável da docência em classe hospitalar.

O olhar diferenciado, referido pela autora servirá de apoio, em todas as relações estabelecidas no ambiente hospitalar, e possibilitará a escuta sensível. Para Ortiz e Freitas (2005, p. 66): "O professor, sensível ao estado conflituoso do paciente, reveste sua ação de educar num ato de companheirismo, de disponibilidade para estabelecer parcerias e cumplicidades". Neste sentido é fundamental o preparo específico para atuar nesta área, visto que além de todas as exigências formalizadas para a execução do trabalho docente é necessário possuir controle emocional, flexibilidade e sensibilidade.

O pedagogo hospitalar pode desenvolver diversas atividades com as crianças, sendo que estas dependem das suas condições de saúde e de sua disposição. As atividades geralmente assumem caráter lúdico possibilitando a recreação, a interação entre as crianças e também que elas se sintam em um ambiente familiar, desmistificando a ideia de hospital como um ambiente frio e triste. Conforme apresenta Ortiz e Freitas, (2005, p.54): "Esta educação focaliza o paciente-aluno como sujeito inventivo, que consegue se adaptar ao novo e sair das amarras do estado de vitimização".

Matos e Mugliatti (2009) distinguem duas possibilidades de trabalho educacional a ser desenvolvido no contexto hospitalar, que são: hospitalização escolarizada e classe hospitalar. De acordo com as autoras, a hospitalização escolarizada diz respeito ao atendimento individualizado oferecido a criança de acordo com suas necessidades, sendo que geralmente há uma orientação da escola sobre o trabalho a ser desenvolvido. Já a Classe Hospitalar refere-se ao trabalho diversificado, realizado em uma sala no hospital, destinado ao atendimento das crianças hospitalizadas, neste, são acolhidas todas as crianças que apresentam condições de realizar as atividades, sem que haja separação por idade ou ano escolar. Neste espaço são propostas ações que buscam além da aprendizagem, a interação das crianças, pois são realizadas atividades em grupos.

Nas duas propostas são desenvolvidas diversas ações que tem como objetivo a aprendizagem por meio de vivências lúdicas, sendo que os recursos lúdicos são essenciais para o alcance dos objetivos junto a crianças e adolescentes hospitalizados. Rocha e Sousa (2012) apresentam como possíveis atividades a ser desenvolvidas no ambiente hospitalar as brinquedotecas, a contação de histórias, as aulas individuais ou em grupo para o desenvolvimento de conteúdos específicos, o trabalho com as datas comemorativas e atividades artísticas. Ainda de acordo com as autoras o atendimento hospitalar traz benefícios às crianças e adolescentes internados, relacionados à saúde física, mental e social, pois permitem ações, que valorizam:

- A comunicação afetiva como caminho de superação às dificuldades enfrentadas pelas crianças doentes;

- O olhar da criança para o ambiente hospitalar, não como lugar de dor e angústia, mas também de aprendizado;

- Não interromper com o processo de escolarização;

- A construção de espaços de convivência coletiva entre crianças, familiares, estudantes e professores (Não isolamento) - classes hospitalares e brinquedotecas;

- O reestabelecimento das relações sociais;

- A restauração da autoestima, comprometida por causa de medicamentos, dor e angústia;

- O vínculo que o paciente-aluno mantém com o mundo exterior. (ROCHA; SOUZA, 2012, p. 09),

Entretanto, antes de iniciar o trabalho pedagógico com a criança hospitalizada é preciso considerar suas experiências com a doença e com o hospital e os significados que cada uma constrói frente ao processo de hospitalização, pois de acordo com Kudo e Maria (2009) cada criança ou adolescente reage de uma forma a doença, ao tratamento e a hospitalização, sendo que em muitos casos é marcante o sofrimento devido às inúmeras perdas que o processo de internação acarreta. As autoras ressaltam que: 
A criança, ao ser hospitalizada, é retirada de seu meio social habitual. Ela é inserida em um ambiente desconhecido, com pessoas estranhas ao seu convívio e, sentindo-se ameaçada, surgem medos e fantasias a respeito de sua doença e do que vai acontecer. Em muitos momentos, a criança fala sobre a falta daquilo que lhe é familiar e as restrições encontradas durante a hospitalização. Um dos temas mais recorrentes é a saudade de casa (KUDO; MARIA, 2009, p.1) .

Neste sentido, é importante ampliar as formas e medidas de atendimento destinadas às crianças e adolescentes, pois, a hospitalização, na maioria das vezes, é um grande desafio a ser enfrentado. Possibilitar formas eficazes de superação do ambiente para a criança é tarefa árdua e constante, porém é um processo que origina bons resultados.

De acordo com Matos (2010, p.47), "A presença do professor neste momento de fragilidade retoma na criança a confiança automaticamente; como num passe de mágica a autoestima é recuperada e surge um estímulo vital que inibe a dor e a tristeza", isto faz com que a presença do professor seja vista como mais um profissional a contribuir de forma positiva no tratamento da criança hospitalizada. A autora pontua ainda que:

Os profissionais de saúde envolvidos no processo de cuidado e tratamento do paciente/aluno relatam que a criança que recebe algum tipo de atenção educacional durante o internamento tende a ser mais receptiva, calma, e realiza as tarefas terapêuticas com disposição, o que auxilia em sua recuperação. (MATOS, 2010, p.43)

Em se tratando da criança ou adolescente em tratamento oncológico os desafios são maiores, visto que a medicação agride o organismo em todas as áreas, desencadeando o cansaço, a sensação de fadiga ou até mesmo a falta de energia, que são sintomas mais comuns. A criança deve receber maior atenção de toda a equipe hospitalar, pois a doença vem acompanhada de vários sintomas, como dores constantes e grande desconforto causado pelo tratamento e pelos exames realizados. De acordo com Almeida (2008), nesta fase a criança experimenta uma situação de enfrentamento constante com a sua própria morte, pois além do tratamento ser prolongado é também marcado por seus procedimentos invasivos e dolorosos.

Neste caso, a pedagogia hospitalar possibilita que a criança ou o adolescente tenha recursos de enfrentamento diferenciados para lidar com a doença e com o tratamento.

\section{A PEDAGOGIA HOSPITALAR DESENVOLVIDA EM HOSPITAL ONCOLÓGICO}

A metodologia empregada para conhecer o trabalho desenvolvido pelos profissionais que atuam em uma escola especializada no atendimento de pacientes em tratamento oncológico bem como os resultados deste trabalho foi realizada uma pesquisa de campo, qualitativa, exploratória, na escola Schwester Heine, instalada no Hospital AC Camargo Cancer Center, localizado na cidade de São Paulo, que é referência nacional no tratamento oncológico infantil, em pesquisas relacionadas ao câncer no Brasil e também possui um diferencial no trabalho pedagógico hospitalar.

Essa foi a primeira instituição escolar inserida em um hospital oncológico brasileiro, sendo que até 1987, ano de fundação da escola, existiam no país apenas classes hospitalares, que continuam, até hoje, sendo a maioria. Carmen Prudente, esposa de Antonio Prudente (fundador do Hospital) e a pedagoga Maria Genoveva Vello idealizaram a escola com a proposta de evitar que os pacientes da oncologia pediátrica perdessem aulas e provas, por não terem acesso ao convívio escolar em razão do tratamento. Elas contaram com o auxílio de Alois Bianch, o primeiro oncologista pediátrico do hospital que se destacava por possuir um olhar voltado para o bem estar da criança. A escola especializada Schwester Heine recebeu esse nome em homenagem à enfermeira alemã Heine, vinda da Segunda 
Guerra Mundial, para trabalhar no hospital.

A Escola Especializada/hospitalar Shwester Heine tem como objetivos: propiciar ambiente adequado facilitando uma possível reintegração escolar, integrar o aluno/paciente à sociedade, tornar os períodos de internação e tratamento o mais agradável possível, proporcionar total adesão ao tratamento e criar condições para que o aluno/paciente não perca o ano letivo. A equipe da escola, que conta com nove professores e uma gerente educacional, compreende que as classes hospitalares são garantia do direito constitucional à educação e que ela tem um valor educacional terapêutico, pois amplia a assistência e as ações para humanização da internação e do tratamento oncológico, minimizando o impacto da doença e do tratamento, auxiliando na recuperação e impedindo a segregação.

A pesquisa de campo contou com a aplicação de dois modelos de questionários, devidamente aprovados pelos Comitês de Ética das instituições proponente e promitente, sendo um para a gestora educacional e outro para os professores. Participaram da pesquisa sete dos nove professores e a gestora educacional.

Dos professores que responderam o questionário, seis são do sexo feminino e um masculino e possuem idades variadas, sendo que um possui entre 20 a 30 anos, dois de 31 a 40 anos, dois de 41 a 50 e dois de 51 a 60 anos. Todos possuem graduação em Pedagogia e um também graduação em Matemática e Administração. Possuem também Pós-Graduação, sendo que cinco professores possuem formação em Educação Especial, três em Psicomotricidade, dois em Psicopedagogia e três em Pedagogia Hospitalar. A maior parte dos professores atua apenas em meio período no hospital e um no período integral. Eles são contratados e cedidos ao hospital pela secretaria de Educação do Estado de São Paulo e pela Secretaria Municipal de Educação.

A gestora educacional da Escola Hospitalar possui 51 anos de idade, quinze anos de magistério e um exercendo a função de Gestora. Cursou graduação em Pedagogia, especialização em Psicopedagogia, mestrado em Tecnologia e Educação e doutorado em Educação e está há quinze anos envolvida com a temática da Pedagogia Hospitalar. Ela relata que na escola é possível observar um grande envolvimento e comprometimento de todos os profissionais que nela atuam e que as intervenções na escola hospitalar são realizadas: "Sem dúvida alguma, com profissionalismo, afetividade, ética e muito amor".

A gestora afirma que há uma grande preocupação com a qualidade do serviço educacional oferecido, pois a escola executa projetos educativos e incentiva a utilização constante de recursos lúdicos e ressalta: "Atuamos com projetos e o lúdico permeia toda a prática. Além do trabalho com projetos, realizamos apoio pedagógico e acompanhamento escolar com os alunos-pacientes que necessitarem". E a respeito das práticas cotidianas apresenta que:

A relevância do trabalho no contexto hospitalar é tanta quanto o trabalho na Escola regular. Entretanto, o modo de ver e pensar do profissional da Educação efetiva a diferença em sua prática, em sua formação e no seu dia a dia. A criança, certamente, reagirá melhor no tratamento quando o Hospital disponibilizar o serviço da Classe Hospitalar em seu ambiente.

As respostas da gestora educacional possibilitaram conhecer mais sobre a história e o funcionamento da escola e compreender a importância do trabalho desenvolvido com a Pedagogia Hospitalar, bem como o compromisso da instituição em auxiliar as crianças e adolescentes.

\subsection{A pedagogia hospitalar na percepção dos professores}

Com a pesquisa de campo realizada junto aos sete professores que atuam na escola especializada 
foi possível compreender como organizam suas ações e práticas pedagógicas, bem como conhecer os desafios que enfrentam no desempenho de suas funções. Visto que, para eles, um modelo de educação não formal, fora dos muros da escola, tem sido de grande relevância para as crianças e adolescentes hospitalizados durante o tratamento oncológico e tem contribuído para melhoria do bem-estar e do enfrentamento da doença e do tratamento em si.

O trabalho docente desenvolvido no contexto hospitalar, na percepção dos professores que participaram da pesquisa, é uma ação de extrema importância em todos os aspectos, sendo recurso significativo durante o processo de hospitalização, valorizando a saúde e a educação, pois como afirma a professora A: "Uma grande conquista em que colocamos de uma forma igualitária a educação e a saúde como foco prioritário da promoção à vida".

Para melhor atender as necessidades dos pacientes/alunos, este trabalho é realizado de forma multi/inter/transdisciplinar, ou seja, são áreas diferentes que necessitam ser abordadas de forma integrada, possibilitando maior vínculo com a escola, pois como afirma Mattos e Mugliatti (2009.p.47):

A educação que se processa, por meio da Pedagogia Hospitalar, não pode ser identificada como simples instrução (transmissão de alguns conhecimentos formalizados). É muito mais que isto. É um suporte psico-sociopedagógico dos mais importantes, porque não se isola o escolar na condição pura e doente, mas sim, o mantém integrado em suas atividades da escola e da família e apoiando pedagogicamente na sua condição de doente.

De acordo com os professores, os maiores desafios ou dificuldades encontradas na execução do trabalho docente hospitalar são, dentre outras, conhecer sobre a doença, o quadro clínico e o tratamento que o aluno/paciente está realizando e lidar com as emoções, pois, é necessário que o professor tenha algumas informações para direcionar as propostas e as formas de intervenção, além de preparar-se emocionalmente para lidar com o sofrimento causado pelo tratamento e com o óbito, que pode ocorrer. A esse respeito, o professor $\mathrm{C}$, aponta: "Nossos alunos pacientes estão realizando um tratamento muitas vezes agressivo e prolongado. Cabendo ao Pedagogo Hospitalar desenvolver pesquisas nesse âmbito". O professor D afirma: "Trabalhar com crianças com câncer, saber controlar o emocional e dar o melhor na ajuda e fazendo a criança feliz, acima de tudo". O professor E enfatiza que: "Meu maior desafio é lidar com os óbitos que ocorrem [...]".

Sendo assim, Fonseca (2008, p.29) ressalta que:

O professor da escola hospitalar é, antes de tudo, um mediador das interações da criança com o ambiente hospitalar. Por isso, não lhe deve faltar, além de sólido conhecimento das especificidades da área da educação, noções sobre as técnicas terapêuticas que fazem parte da rotina da enfermaria, e sobre as doenças que acometem seus alunos e os problemas (mesmo os emocionais) delas decorrentes, tanto para as crianças como também para todos os familiares e para as perspectivas de vida fora do hospital.

O trabalho do docente hospitalar envolve ações complexas, pois além de ser necessário possuir conhecimentos em diversas áreas acadêmicas, no contexto hospitalar é fundamental saber lidar com a doença e com os desafios que ela impõe à criança e à família, carecendo de condições emocionais para enfrentar as variadas situações. Para o professor F, as dificuldades podem ser superadas com um trabalho em grupo e afirma: "As dificuldades encontradas são sanadas através do trabalho em grupo. Como lidar com a morte e com o número excessivo de atendimentos, são questões a serem discutidas em grupo".

É válido ressaltar a importância do estabelecimento de parcerias com os profissionais da saúde que acompanham a criança, como médicos das diversas especialidades, enfermeiros, nutricionistas, 
psicólogos, entre outros, pois o contato direto com eles possibilitará ao pedagogo obter mais informações sobre cada caso, minimizando as dificuldades narradas.

Um dos aspectos a salientar para o sucesso das intervenções educacionais realizadas no contexto hospitalar, de acordo com os professores, está o vínculo afetivo com a família e com a criança, sendo que este, na percepção deles, é construído a partir de uma escuta sensível, sabendo ouvir, levando em consideração o momento de fragilidade em que todos se encontram, como aponta a professora A: "Serenidade, equilíbrio, respeito, além da escuta sensível, são os pontos fortes de um professor de classe hospitalar, sem perder a intencionalidade pedagógica, para que a criança e a família se sintam acolhidos, amparados e seguros".

A este respeito o professor G também pontua que: "É fundamental "OUVIR", no ambiente hospitalar, o professor está em constante aprendizagem e por meio desta escuta que as informações da vida desta criança, desta família tornam a experiência da hospitalização positiva, para o crescimento e desenvolvimento da criança, possibilitando um vínculo afetivo tanto com a criança quanto com a família".

Estes apontamentos correspondem às afirmações de Assis (2009) quando defende que além da experiência profissional é fundamental que o pedagogo que atua com crianças hospitalizadas desenvolva um olhar diferenciado e um escuta sensível e com Ortiz e Freitas (2005, p. 66) quando ressaltam a necessidade do estabelecimento de vínculos com a criança e com a família ao pontuar que: "O professor, sensível ao estado conflituoso do paciente, reveste sua ação de educar num ato de companheirismo, de disponibilidade para estabelecer parcerias e cumplicidades". Neste sentido, é fundamental que o professor se empenhe no estabelecimento de vínculos favoráveis à aprendizagem.

De acordo com os professores, as atividades propostas na Escola Especializada Schwester Heine, são desenvolvidas por meio de projetos, acompanhamento escolar, apoio pedagógico e atividades lúdicas, de acordo com a faixa etária de cada aluno, pois eles possuem, além das idades diferentes, diversos níveis e estilos de aprendizagem. São atividades planejadas em grupo, visando atender as expectativas dos alunos/pacientes e os projetos são temáticos, possibilitando o trabalho com artes (recortes/colagens) e vários outros campos de conhecimento. $\mathrm{O}$ professor $\mathrm{G}$ afirma que:

Primeiramente vamos entender quais as linhas de conhecimento em que a escola atua, temos o nosso próprio projeto pedagógico (planejamento), acompanhamento escolar (parceria com a escola de origem da criança), apoio pedagógico (atendimento individualizado, sanando dificuldades). Lembrando que cada aluno é ÚNICO, o atendimento pedagógico hospitalar é realizado com alunos com idades e níveis de conhecimento diferentes (multisseriados e multietários).

A respeito dos temas dos projetos, a professora B informa: "Trabalhamos com projetos, este ano o tema é "Olimpíadas 2016". As atividades são escritas, recorte e colagem, desenho, pesquisa, de acordo com a série do aluno-paciente". Em relação às atividades artísticas, a professora A relata: "Procuro, por meio de minha prática pedagógica, imprimir um cunho artístico nas atividades, pois sei da importância das artes plásticas e visuais na complementação do tratamento". Em relação ao trabalho com Arte no ambiente hospitalar Mattos (2009, p. 90) defende que: "A arte torna-se um importante papel para a criança/adolescente hospitalizado, sendo um instrumento por muitas vezes transformador. Proporcionando que o enfermo consiga "falar" por meio de trabalhos artísticos sobre sua história e seus sentimentos". Kudo e Maria (2009, p. 78) afirmam que: "Além das atividades lúdicas, é importante também oferecer e incentivar atividades diversificadas para estimular o processo de aprendizagem tais como desenho, pintura, colagem, artesanato e trabalhos com sucata."

Ao propor atividades e planejar o trabalho a ser desenvolvido, é fundamental que o pedagogo leve em consideração o momento de fragilidade física e emocional vivenciada pelo aluno/paciente, bem como 
suas peculiaridades e os objetivos das ações desenvolvidas, pois estas precisam respeitar suas possibilidades e interesses, visto que é de suma importância identificar as condições da criança antes de apresentar a proposta de atividade, pois deve ser levada em consideração a realidade de cada um. A este respeito o professor G ressalta: "Respeitar a condição física e psicológica da criança é essencial, quando eu entendo essa criança, o planejamento é a primeira etapa antes de qualquer tomada de decisão e saber com quem eu vou trabalhar, torna o atendimento especializado". E o professor E reafirma: "As crianças fazem as atividades de acordo com o estado em que se encontram. Muitas vezes querem realizar atividades mesmo não estando bem. O fato de estarem fazendo atividades os mantém vivos".

A professora A também se refere à realização das atividades e à escola como sinais de vida e afirma: "Escola é vida e a criança hospitalizada sente uma maior necessidade de desenvolver atividades escolares, estabelecendo um vínculo necessário com o mundo fora do hospital. As atividades passam a ser mais prazerosas".

Os professores também ressaltaram os aspectos positivos da atuação na pedagogia hospitalar, pois de acordo com F: "É uma relação permeada por aprendizagens" e para o professor E: "É uma relação muito gratificante na qual há diálogo e realização de atividades com as quais a criança se mantem entretida esquecendo que está num ambiente hospitalar". Também reconhecem os resultados do trabalho realizado, sobretudo por contribuir com os aspectos emocionais, cognitivos e sociais da criança hospitalizada.

Para o professor A: "A ligação entre professor e a família se torna tão grande e intensa que ao receber alta, existe uma mescla de sentimentos, alegria e tristeza e às vezes até insegurança por ficar longe de um ambiente protetor, em que os sentimentos mais nobres se destacam”. Já para o professor G:

Assim como o aluno-paciente os familiares também participam da escola. A devolutiva vem muitas vezes pela verbalização dos familiares na satisfação, segurança e confiança no trabalho pedagógico. A resposta da escola de origem é satisfatória na aprovação do aluno atendido e muitas vezes, superada aos demais. Hoje o hospital não VIVE sem a escola.

$\mathrm{Na}$ concepção dos professores, o trabalho pedagógico hospitalar resultará em maiores possibilidades de interação social e de sua inserção na sociedade, na escola e nos demais ambientes após o tratamento. Para a professora A "A escola é um espaço sócio-cultural importantíssimo para a formação deste aluno/paciente, onde diante de tanto sofrimento, conseguimos minimizar a dor física e moral." Já o professor G, afirmou que:

Trabalhar em classe hospitalar é uma experiência única, fantástica e muito rica. É ter uma oportunidade de você fazer agrupamentos produtivos dos alunos-pacientes se integrarem e aprenderem juntos mesmo com a diversidade que há, proporcionando o nosso principal objetivo a inserção e a reinserção escolar do aluno-paciente à vida.

Estas afirmativas correspondem ao posicionamento de Ortz e Freitas (2005, p.42) quando ressaltam:

A intervenção educacional assume um risco de insinuar a existência do mundo extrahospitalar - a escola - como agenciadora de processos de aquisição de aprendizagem, desenvolvimento de competência intelectual e interação entre seus pares, compondo um novo quadro de qualidade de vida, entrecruzando sentidos e construindo sentidos para ressignificar o adoecimento.

De forma geral, os professores demonstram compreender as especificidades do trabalho a ser desenvolvido no ambiente hospitalar, bem como a necessidade de buscar recursos para o enfrentamento 
dos desafios que a Pedagogia Hospitalar impõe.

Para finalizar o questionário, foi solicitado que os professores relatassem um fato marcante ocorrido durante o trabalho como docente hospitalar. Dada a relevância dos relatos, estes são apresentados na íntegra a seguir:

Diante de tantos fatos marcantes, o que me sensibilizou também foi quando uma família perdeu o seu filho pré-adolescente e, durante alguns meses, a mãe continuou frequentando a escola da internação, pois ela sentia a presença dele. Foi muito importante respeitar esse momento de elaboração do luto na família. (Professor A)

Como é meu primeiro ano, posso enfatizar uma atividade do projeto Olímpiadas Criação da mascote da escola. (Professor B)

Ao participar do Projeto Afeto, realizado pela pediatria, enquanto diretora teatral tive a percepção exata do valor do educador na integração do grupo multidisciplinar do hospital. (Professor C)

Estou a quase dois meses, um paciente me chamou atenção, jamais imaginei na vida. Todos os dias antes da minha pessoa chegar, tinha um aluno me esperando para aplicar as atividades para ele, bem antes do meu horário, em pouco tempo nunca imaginei uma criança gostar tanto de mim, a ponto de acordar cedo para me esperar para as atividades. É uma coisa que me deixava bastante comovido, hoje não o vejo mais, mas, sinto saudades, ele falava "meu professor querido chegou", eu gostava do dia com que aquilo chegava aos meus ouvidos. Se felicidade existe, então sou muito feliz. (Professor D).

Uma aluna paciente que ficou conosco fazendo o acompanhamento escolar por um ano e meio. Quando voltou à escola de origem, depois de já estar há mais de seis meses fora de tratamento, a mãe relatou que na reunião de pais, os professores elogiaram a aluna, dizendo que ela estava totalmente readaptada e melhor que muitos alunos que frequentaram a escola durante o ano todo. Esta aluna é da cidade de Cuiabá. (Professor E)

O reconhecimento dos pais em relação à importância do acompanhamento escolar. (Professor F)

A minha primeira perda, o meu primeiro luto. Mariana uma linda menina de 16 anos, apaixonada pela vida, pela arte, pela música e pela literatura. Nos conhecíamos há cinco meses. A nossa última aula; análise do poema "Amor é um fogo que arde sem se ver", Luiz Vaz de Camões. Depois disso foi impossível ensinar sem amor. Ela era uma criatura que inalava amor e sua presença é eterna. (Professor G)

É válido destacar que os relatos, embora imbuídos de valor sentimental, em sua maioria apresentam situações e vivências pedagógicas, demonstrando que os profissionais compreendem seu papel de educador e a relevância de seu trabalho para o tratamento dos alunos/pacientes.

A realização desta pesquisa de campo, além da relevância, possibilitou conhecer a atuação de professores/pedagogos junto a crianças e adolescentes em processo de hospitalização durante o tratamento oncológico, bem como os resultados positivos do trabalho desenvolvido e o compromisso da Escola Especializada Schwester Heine com a qualidade de vida dos alunos/pacientes em todos os seus aspectos.

\section{CONSIDERAÇÕES FINAIS}

A Pedagogia Hospitalar constitui um campo de atuação do pedagogo que precisa ser mais bem conhecido e ter seu atendimento ampliado devido aos benefícios que propicia às crianças e adolescentes 
hospitalizados. Sua implantação nos hospitais além de atender a um dispositivo legal, contribui para a melhoria da qualidade de vida destas pessoas e resultam em um impacto positivo no tratamento em curso.

As ações da Pedagogia Hospitalar desenvolvidas junto a alunos/pacientes em tratamento oncológico na Escola Especializada Schwester Heine têm se mostrado eficazes no tratamento das crianças e adolescentes em situação de internação prolongada, e refletem positivamente ao longo do tratamento e também no processo pós internação que envolve a reinserção na escola e na sociedade.

O profissional que pretende atuar nesta área precisa de formação específica, e, além dos conhecimentos teóricos e práticos referentes ao processo de aprendizagem, às doenças e tratamentos, é fundamental que se identifique com o trabalho a ser desenvolvido, demonstre estabilidade emocional e resiliência para enfrentar os desafios inerentes a este campo de atuação além de ser essencial que pratique o olhar diferenciado e escuta sensível. Também é necessário que desenvolva habilidades para trabalhar em grupo, pois a parceria com a família, com a escola de origem da criança ou do adolescente e com os demais profissionais da saúde é fundamental para o sucesso das intervenções educativas.

A área da Pedagogia Hospitalar mais difundida e carece de estudos e pesquisas que proporcione a construção de um corpo teórico consistente que possibilite sustentação teórico-prática de suas ações. Atualmente Os profissionais para atuarem nesta área recorrem à formação em Educação Especial e/ou a Psicopedagogia para embasar e complementar o trabalho realizado. Além de ser urgente a necessidade da implantação de Políticas Públicas Educacionais e de Saúde que estimulem a proliferação deste serviço nos hospitais.

\section{AGRADECIMENTOS}

À Fundação Educacional de Ituverava pela viabilidade do Projeto e à Escola Especializada Shwester Heine da Fundação Antônio Prudente - Hospital AC Camargo Câncer Center pela possibilidade e realização da pesquisa.

\section{REFERÊNCIAS}

ALMEIDA, F. Brinquedo no Hospital: Preparando a criança para a cirurgia cardíaca. In: ASSOCIAÇÃO BRASILEIRA DE BRINQUEDOTECAS. Brinquedoteca hospitalar: isto é humanização. Drauzio Viegas (org.). 2. ed. Rio de Janeiro: Wak , 2008.

ASSIS, W. Classe Hospitalar: Um olhar pedagógico singular. São Paulo: Phorte, 2009.

BRASIL. Conselho Nacional dos Direitos da Criança e do Adolescente. Estatuto da Criança e do Adolescente Hospitalizado. Resolução n 41 de outubro de 1995.

BRASIL. Conselho Nacional dos Direitos da Criança e do Adolescente. Resolução n. 41, de outubro de 1995. Diário Oficial da União 17 out. 1995.

BRASIL. Constituição (1988). Constituição da República Federativa do Brasil. Brasília, DF. Senado, 1988.

BRASIL. Ministério da Educação e do Desporto. Lei de Diretrizes e Bases da Educação Nacional. Brasília, 1996.

BRASIL. Ministério da Educação. Classe hospitalar e o atendimento pedagógico domiciliar: estratégias e orientações. / Secretaria de Educação Especial. Brasília: MEC, SEESP, 2002. 
BRASIL, Ministério da Saúde. Instituto Nacional do Câncer. Estimativas da incidência de câncer no Brasil - 2010. Disponível em: <http://www.inca.gov.br>. Acesso em: 20 set. 2016.

CONANDA. Conselho Nacional dos Direitos da Criança e do Adolescente. Estatuto da Criança e do Adolescente Hospitalizado. Disponível em: < http://www.direitosdacrianca.gov.br/ >. Acesso em 20 set. 2016.

DIREITOS da criança e do adolescente hospitalizados. Diário Oficial, Brasília, 17 out. 1995. Seção 1, pp. 319-320.

ESTEVES, C. R. Pedagogia hospitalar: um breve histórico. 2008. Disponível em: < http://portal.educacao.salvador.ba.gov.br/site/documentos/espaco-virtual/espaco-educacao-saude/classeshospitalares/WEBARTIGOS/pedagogia\%20hospitalar....pdf Acesso em: 20 jul. 2016.

FONSECA, E. S. Atendimento escolar no ambiente hospitalar. 2.ed. São Paulo: Memnon, 2008.

HANZE, A. Classes Hospitalares e o direito à educação. Barretos. 2011. Disponível em: <http://educador.brasilescola.uol.com.br/politica-educacional/direito-educacao.htm> . Acesso em 10 ago. 2016.

KUDO, A. M. MARIA, P. B (org). O Hospital pelo olhar da criança. São Caetano do Sul: Yends, 2009.

MATOS, E. L. M, MUGLIATTI, M. M. T. Pedagogia Hospitalar: A humanização integrando educação e saúde. 4. ed. Petrópolis: Vozes, 2009.p.181.

MATOS, E. L. M. Escolarização Hospitalar: educação e saúde de mãos dadas para humanizar. Petrópolis: Vozes, 2010, p.226.

MELNIK, M. X; KACIA de C. Contapramim: historias que acolhem e que ajudam a curar. As histórias e a ludicidade na pedagogia hospitalar. Curitiba Paraná: Appris, 2015.p.162.

ORTZ, L. C. M, FREITAS, S. N. Classe Hospitalar: caminhos pedagógicos entre saúde e educação. Santa Maria: UFSM, 2005.

ROCHA, A. S. H; SOUSA, I. N. B. Pedagogia Hospitalar: um direito da criança e do adolescente. Maranhão: Etos. 2012. (Cartilha Informativa). 
